\title{
Contribución al estudio de la emigración rifeña a Argelia, 1852-1956
}

Mimun Ahmed Aziza

\section{Resumen}

El presente artículo trata de un aspecto muy importante de la historia contemporánea del Rif: el de la emigración de trabajadores rifeños a Argelia, fenómeno que marcó la memoria de los rifeños y su historia durante todo un siglo. Las primeras migraciones se remontan a la segunda mitad del siglo XIX y proseguirán hasta la independencia de Marruecos en 1956.

Oh, Moha, palomo mío, tú que vas a Tasala a la siega. Vuelve, vuelve, oh, hermano mio, basta para ti de miseria! Ya los muchachos duermen en tu casa $Y$ los herederos se reparten tu tierra

Canción popular rifeña Oranesado

1. Las relaciones entre el nordeste de Marruecos y el

El estudio de la emigración rifeña a Argelia, particularmente al Oranesado, nos lleva a evocar las importantes relaciones económicas y sociales que existran entre el Oranesado y el nordeste marroquí. 
Hacia fines del siglo XIX, comerciantes y hombres de negocios de Orán y de Argel empezaron a interesarse por esta región que consideraban, desde el punto de vista geográfico, una prolongación natural de la Argelia francesa. En Le Maroc inconnu, A. Moulièras da del Rif la imagen de un país muy rico y muy poblado al que Francia, antes que cualquier otra nación, tendría interés en ocupar.

Desde principios de este siglo, el Bulletin de la Société de Géographie et d'Archéologie d'Oran y el Bulletin du Comité de l'Afrique française publicaban varios estudios sobre la región "de influencia española", como se decía en la época ${ }^{1}$.

Todos estos estudios insisten en la comunidad de intereses económicos entre estas dos regiones, la cual se veía reforzada por vínculos étnicos e históricos.

En 1916 E. Déchaud ${ }^{2}$ afirmaba que durante más de mil años la frontera entre ambas regiones era imprecisa y que, con frecuencia, una parte del Oranesado pasó a formar parte de Marruecos e, inversamente, el Este marroquí pasó a pertenecer al Oranesado.

Las relaciones comerciales entre el Rif y el Oranesado se remontan a los tiempos más remotos. Durante siglos, Orán fue el puerto del gran mercado del Rif. La conquista francesa contribuyó a ampliar esas relaciones al facilitar los medios de comunicación y emplear todos los años, a cambio de un salario remunerador, de unos 20 a $30 \mathrm{mil}$ rifeños ${ }^{3}$.

La colonización francesa puso también de manifiesto los vínculos existentes entre el Rif y el Oranesado cuando el emir Abd-elKader, jefe de la resistencia argelina, que era de ascendencia rifeña, tuvo que refugiarse en Marruecos y hallo apoyo en las tribus del Rif.

(1) Señalo, en particular, el informe redactado por el ingeniero Manuel Becerra, que fue traducido al francés por G. Aucher y publicado con el título "La région des Guelaya (Rif) et le chemin de fer de Melilla aux mines des Beni Bou Ifrour", in Bulletin de la Société de Géographie et d'Archéologie d'Oran, junio de 1909, p. 368-391. También el artículo de J. Goulven: "La zone de Melilla", in Renseigments coloniaux, publicado por el Comité de l'Afrique française, febrero de 1929, y A. Bernard en Les confins algero-marocains, París, Armand Colin, 1911 , así como otros estudios que conceden un interés especial a esta región.

(2) Ed. Déchaud: "Une mission commerciale au Maroc", in Bulletin de la Société de Géographie et d'Archéologie d'Oran, p. 31.

(3) Esta es la cifra que citan la mayoría de los autores de la época de que se trata: A.

Moulièras, J. Goulven, L. Milliot, H. Duveyrier, etc. 
Al declarar a Melilla puerto franco en 1881, los españoles asestaron un golpe decisivo a la corriente comercial entre el Rif y el Oranesado. Sin embargo, los vínculos del Rif con Argelia no quedarán completamente cortados, ya que las hostilidades que estallaron entre los españoles y las tribus de Guelaya en 1893 tuvieron por resultado el cierre del mercado de Melilla y, más adelante, los rifeños seguirán acudiendo a Nemours, Marnia y Tremecén para comprar artículos de consumo necesarios como jabón, té, café, etc ${ }^{4}$.

La emigración de trabajadores rifeños a Argelia desempeño un importante papel en la ampliación de las relaciones ya existentes entre la economía colonial francesa de Argelia y la economía del nordeste marroqur.

\section{La emigración y la sociedad rifeña}

El movimiento migratorio es un fenómeno muy antiguo en el Rif. Pese a que la sedentarización es muy antigua, una parte importante de la población rifeña se vio obligada a emigrar para buscar recursos complementarios 5 . Este fenómeno refleja la diferencia entre la escasez de los recursos existentes y la alta densidad demográfica. El Rif conseguía a duras penas alimentar a sus habitantes. La abundante literatura rifeña a propósito de la emigración constituía una necesidad cuyas causas analizaremos más adelante.

Si el rifeño se encontraba ya durante una buena parte del año "inactivo", disponible para expatriarse, a ello hay que sumar las hambrunas que sufría el Rif periódicamente. A fines del siglo XIX, el marqués de Segonzac señalaba que en el Cabo de Tres Forcas, que él visitó, no había llovido aquel año en febrero y que la prosperidad era excepcional, pero que desde hacía seis años las lluvias eran muy escasas $y$, al no bastar ya las cosechas, los hombres jovenes se veían obligados a emigrar ${ }^{6}$.

La gran hambruna que tuvo lugar durante la segunda guerra mundial marcó profundamente la memoria de los viejos rifeños, ya que

(4) Ed. Déchaud, art. cit. p. 32.

(5) Según L. Milliot, en los años treinta una cuarta o quinta parte de la población total de algunas tribus rifeñas se veía obligada a desplazarse al exterior, sobre todo a Argelia, para poder subsistir.

(6) Segonzac (Marqués de), Voyages au Maroc (1899-1901), París, 1911. 
alcanzó dimensiones excepcionales, particularmente la del año de 1941, que los rifeños designaron "el año del hambre" 7. Esta provocó el éxodo masivo de los campesinos más pobres a Argelia, la región del Garb y la región de Yebala, sobre todo a las ciudades de Tánger y Tetuán. En 1957. D.M. Hart señalaba que en Tánger el número de rifeños podía estimarse de 25.000 a 30.000 personas, llegadas en su mayoría "a pie y medio muertas de hambre en $1945 " 8$.

\section{Argelia}

\section{Antigüedad de la emigración de trabajadores rifeños a}

Esta emigración empezó a principios de la segunda mitad del siglo XIX, es decir, desde los primeros trabajos de puesta en explotación de tierras para la colonización en Argelia:

"El 18 de noviembre del año 1852, los españoles de Melilla se apoderaron, sin duda como represalia, de una barca mercante perteneciente a gente de Guelaya y que se dirigía a Orán donde los trabajadores de esta tribu vienen ahora cada vez más cada año a alquilar sus brazos a los colonos en la temporada de la siega" 9 .

Apoyándose en documentos del Archivo Histórico Nacional de Madrid, D.M. Hart señala que la primera mención de relaciones de los Ait Waryaghar (Beni Uriaguel) con Argelia se remonta a $1856^{10}$.

En 1895, en Le Maroc inconnu, A. Moulièras indicaba que más de 20.000 rifeños iban a trabajar todos los años a Argelia ${ }^{11}$.

L. Milliot ${ }^{12}$ señala hacia 1934 que esta emigración se re-

(7) "Aam na yua".

(8) D.M. Hart, "Notes on the Riffian Communitiy of Tangier", Middle East Journal, $1957, \mathrm{n}^{2} 11$, p. $153-162$.

(9) H. Duveyrier, "La demière partie inconnue du littoral de la Méditerranée: le Rif", in Bull, Geogr. Hist. et Descr., publicado por el Ministerio francés de industria, París, t. II, p. 127-191.

(10) D.M. Hart, The Aith Waryaghar of the Moroccan Rif. An Ethnography and History. (Wenner-Gren Foundation for Anthropological Research). The University of Arizona Press, 1976.

(11) A. Moulièras, Le Maroc inconnu, vol. I, Exploration du Rif, París, 1895.

(12) L. Milliot, "L'exode saisonnier des Rifains vers l'Algérie", in Bulletin Economique. du Maroc, 1933-1934, p. 313. En 1925, J. Du Taillis declaraba que "desde larga fecha, conocemos al rifeño, que sigue viniendo a Argelia para la siega y la vendimia, como a un trabajador laborioso, valiente y probo, sin duda uno de los colaboradores de la riqueza de 
montaba tan lejos como los recuerdos de las generaciones de esos años, y que desde hacía por lo menos cincuenta años las labores de roturación y de siega eran realizadas por trabajadores rifeños.

Según las informaciones recogidas por $\mathbf{R}$. Bossard ${ }^{13}$ entre "ancianos" del Rif Oriental, las gentes del aduar de Lamsarate, de la comunidad rural de Dar Kebdani, iban a Argelia desde antes de la guerra de 1909 con los españoles. En Taurirt Abduna, en la misma comuna, la emigración a Argelia existía ya en la época del Rogui Bu Hamara, es decir, desde los primeros años del siglo. En el país de Temsamán, la tradición de los aduares de Ijti y de Tizza, de la comuna de Budinar, indica que estos desplazamientos tenían lugar ya en la época de Mulay Hasán I hacia 1890.

En 1965, D. Noin efectuó entrevistas con dos hombres de Ait Wuriechik (Beni Ulichek) cuyos abuelos habian trabajado en Argelia antes del Protectorado español ${ }^{14}$. Nuestras encuestas entre los antiguos obreros de las minas de Beni Bu Ifrur confirman la antigüedad de esta emigración.

Los primeros rifeños que emigraron a Argelia fueron los Guelaya, dada su proximidad a Melilla en donde se embarcaban para Orán.

Esta emigración que, como ya dijimos, se remonta a los primeros años de la segunda mitad del siglo XIX, adquirió mayor importancia en el último decenio del siglo pasado, cuando se estableció un enlace marítimo entre Melilla y Orán. Melilla no fue un verdadero puerto hasta después de $1892{ }^{\text {is }}$, y a partir de entonces los barcos hacían la travesía entre este enclave y Argelia.

La emigración adquirirá mayor importancia con la colonización agrícola española que privó a muchos campesinos de sus tierras sin

nuestra hermosa colonia. Otras veces, demuestra ser un ferroviario inestimable, y muchos kilómetros de ranles de ferrocarril fueron instalados por él, sobre todo en el Oranesado", in Le nouveau Maroc, suivi d' un voyage dans le Rif, p. 332.

(13) R. Bossard, Un espace de migration: Les travailleurs du Rif oriental (Province de Nador) et l' Europe, Universidad de Montpellier, p. 52.

(14) Citado por D.M. Hart, op. cit. p. 88.

(15) J.L. Miège, Le Maroc et l'Europe, París, Presses Universitaires de France, Tomo II, p. 391. "Hasta 1892-1893, Melilla no tenía puerto, sino un fondeadero abierto que, por el viento del Este, ofrecía grandes peligros". 
crear, a nivel local, un número importante de empleos de mano de obra agrícola. De la misma manera que el escaso volumen de los capitales invertidos y la pequeña talla de las empresas industriales no produjeron si no un empleo mediocre de la fuerza de trabajo. A título de ejemplo, el número de personas de la población activa empleadas en la industria en 1953 era sólo de 9.713 , es decir, un $0,94 \%$ de la población total de la zona española ${ }^{16}$. Las minas de Beni Bu Ifrur empleaban de 2.500 a 3.000 obreros en las mejores condiciones de explotación minera. Una empresa de crin vegetal daba empleo a un promedio de 100 a 150 obreros en el campo y de 20 a 30 en la empresa ${ }^{17}$.

El número de los obreros en la pesca podía alcanzar la cifra de 3.000 en las temporadas de gran actividad pesquera ${ }^{18}$.

En general, estos empleos no eran muy importantes en relación con lás necesidades de la población. Por eso, el fenómeno migratorio reviste tanta importancia. La colonización española no realizó transformaciones de la base económica que proporcionaran a los campesinos proletarizados trabajo a nivel local mediante el desarrollo del sector agrícola y el establecimiento de una estructura industrial. Según A. Sakrouchi ${ }^{19}$, la intervención colonial (española) se limitaba a controlar los circuitos de intercambio y de distribución y a ampliarlos a todo el espacio colonizado. Lo que acentuó localmente la masa disponible para la emigración.

Diferentes factores hacían que el número de emigrantes variase de un año a otro: las cosechas en el Rif, la competencia de las máquinas agrícolas más perfeccionadas, los sucesos políticos, las medidas administrativas y las crisis económicas, etc. Pero hasta 1956 la emigración no se interrumpió completamente. Incluso durante la guerra del Rif (1921-1926) gran número de rifeños de la zona española se encontraron aún en Argelia ${ }^{20}$.

(16) Anuario Estadistico del Protectorado Español, Madrid, 1953.

(17) Sierra Mola, La industria en el Protectorado, Tetuán, Imprenta Imperio, 1948, p. 43.

(18) V. Martorell y F. G. Figueras, Acción de España e Marruecos. La obra material, Tetuán, 1948, p. 461.

(19) A. Sakrouchi, La logique économique paysanne et la logique du capital, Tesis de doctorado de tercer ciclo, Universidad de Toulouse, 1982.

(20) J. Du Taillis, La nouveau Maroc, suivi d'un voyage dans le Rif, París, 1925, p. 332. 
Esta emigración, al ser estacional, era designada por los españoles "golondrina".

\section{Causas de la emigración}

En un país como el Rif en donde las condiciones de vida son difíciles, las causas de la emigración no faltan: la dureza del clima y la insuficiencia de la producción agrícola son los factores fundamentales.

Según J.P. Canamas ${ }^{21}$, las fuertes densidades de población en el Rif son antiguas, aunque la importancia actual solo la hayan alcanzado últimamente. En el curso de su historia el Rif aportó a este problema diversos tipos de solución. Los rifeños tuvieron siempre que buscar recursos complementarios para evitar el hambre. R. Bossard afirma que las migraciones de trabajo aparecían, desde hacía 100 a 150 años por lo menos, indisociables de la historia de las poblaciones del Rif oriental y de su evolución economica.

El Rif oriental es desde hace mucho tiempo una región ocupada por campesinos sedentarios muy apegados a la tierra, símbolo de su identidad, aun cuando esa tierra no consiga alimentarlos convenientemente.

Antes del Protectorado español y durante éste, la agricultura fue siempre la base de la vida económica de los rifeños. La sociedad rifeña era una sociedad en la que predominaba el elemento campesino ${ }^{22}$. La tierra constituía el origen de la rivalidad entre las capas sociales cuyos miembros no eran propietarios.

En estas condiciones de superpoblación, la propiedad estaba muy parcelada. Todas las parcelas cultivables, incluso las más pequeñas situadas en las pendientes de las colinas y en los valles estrechos, se explotaban, lo cual provocaba un desequilibrio entre el número de habitantes y la superficie cultivable.

Según B. Pérez ${ }^{23}$, esta superpoblación, que constitufa un

(21) J. P. Canamas, Les sources arabes de l' histoire du Rif préalmoravide, Memoria de "maitrise" de historia, Burdeos, 1973, citado por R. Bossard, op. cit.

(22) María Rosa de Madariaga, in Abd-el-krim et la République du Rif. Actas del Congreso internacional de estudios históricos y sociológicos, 18-20 de enero de 1973, París, Maspero, 1976, p. 354.

(23) "El terreno es pobre en riego y lluvias, aunque la tierra es buena y el trabajo aceptable. Régimen de propiedad muy repartido también favorable. A pesar de estas 
factor negativo insuperable, era la causa principal de la emigración de los rifeños a Argelia. A ello se sumaba la inestabilidad de la economía agricola, la aridez del clima y la irregularidad de las precipitaciones, que representaban una amenaza permanente para la vida de los habitantes y los incitaba a emigrar.

Los años de sequía son los que registraron el mayor número de emigrantes. Tenemos dos grandes ejemplos en la historia del Rif: la hambruna de fines del siglo XIX, señalada por Segonzac ${ }^{24}$, y la que sufrio el Rif durante la segunda guerra mundial. Si se analizan las estadísticas reseñadas en los anuarios estadísticos de los años 40 , comprobamos que esos años de sequía y de hambre registraron una fuerte emigración a Argelia.

Durante el periodo precolonial, la emigración afectaba a todas las capas sociales, pero eran sobre todo los pequeños propietarios y los campesinos sin tierra los que emigraban más, aunque también había comerciantes como era el caso del jerife Mohamed Amezian ${ }^{25}$. Las verdaderas causas de la emigración de obreros rifeños en la época residían pues en la pobreza de recursos de la región. Todos los escritos de viajeros franceses y españoles que visitaron el Rif a fines del siglo XIX y principios del XX, con excepción de los de A. Moulièras, dan del Rif una imagen de país pobre, árido e incapaz de alimentar convenientemente a su población.

En la época colonial, la colonización privó, como ya dijimos, a muchos campesinos de sus tierras, lo cual contribuyo a aumentar la masa disponible para la emigración. Este fue el caso sobre todo de los Ulad Setut y los Beni Bu Yahi. Teniendo en cuenta que las posibilidades de empleo local por parte de los colonos españoles eran muy limitadas, los cabileños se veran obligados a emigrar a Argelia para alquilar sus brazos a los colonos franceses, o a alistarse en el ejército español.

condiciones positivas, la superpoblación crea un factor negativo insuperable", B. Pérez, "Trabajadores rifeños en Argelia", in Conferencias desarrolladas en la Academia de Interventores, 1948-1949. Tetuán, 1959, p. 5-17.

(24)Segonzac(Marqués de), Voyagesau Maroc (1899-1901), París, 1903. R. Bossard, en la obra ya citada, afirma que los ancianos de los aduares de Ijiti, en la comuna de Budinar, se acuerdan de las hambrunas anteriores al Protectorado y dicen que esperaban los socorros de los veleros españoles.

(25) B. Bagdad, La pénétrationespagnole dans le Rif: 1909-1921, tesis de doctorado, Toulouse, 1989, p. 27. 
En efecto, junto a la emigración, el alistamiento en el ejército atrajo a muchos campesinos rifeños en función del aumento y la regularidad de los sueldos que alli se cobraban en relación con los sueldos locales. Hacia los años de 1912-1914, un soldado ganaba entre 60 y 75 francos (de 12 a 15 duros) al mes, mientras que un jornalero agrícola no ganaba más que 45 francos (nueve duros) al mes ${ }^{26}$. En general, la población reclutada en el ejército español pertenecía a las capas sociales más pobres. Se componfa sobre todo de campesinos sin tierra que se instalaron más tarde en pequeños pueblos. Como señala Maŕa Rosa de Madariaga, la insuficiencia de recursos y las malas cosechas que con frecuencia registraba el Rif impulsaban a muchos rifeños a alistarse en el ejército español:

"Los cuatro años anteriores a 1921 habían sido de malas cosechas y, por consiguiente, de hambre en el Rif, y muchos rifeños se alistaban en las fuerzas españolas para huir de la miseria" ${ }^{27}$.

Por estas mismas razones, decenas de miles de rifeños atravesaron el Mediterráneo para participar en la guerra civil española en las filas del ejército franquista ${ }^{28}$.

Las obras públicas y las minas atrajeron sobre todo a los habitantes de las cabilas en donde se desarrollo el trabajo, particularmente en las regiones mineras como la de Beni Bu Ifrur. En éstas últimas, la emigración era muy reducida. F.B. Pérez observa a este propósito: "Es necesario hacer notar que el bereber no es nómada y que si emigra, lo hace siempre impelido por la falta de recursos" ${ }^{29}$. Por esta razón, los que vivían cerca de lugares de trabajo, como las minas y las carreteras en construcción, preferfan trabajar localmente de jornaleros aunque el suel-

(26) D. Seddon, Moroccan peasants. A century of change in the eastern Rif 1870 1970, Folkestone (Kent), Dawson, 1981, p. 152.

(27) María Rosa de Madariaga, "L'image et le retour du Maure dans la mémoire collective du peuple espagnol et la guerre civile de 1936", in L' homme et la Société, $\mathrm{n}^{\circledR} 90$, 1988, p. 73.

(28) La literanura oral rifeña relativa a la guerra civil española muestra claramente que la participación de los rifeños en ésta se debía, en primer lugar, a razones económicas. Esta cuestión ha sido bien estudiada en detalle por la historiadora española María Rosa de Madariaga en "La imagen del moro en la memoria colectiva del pueblo español y retorno del moro en la guerra civil de 1936", in Revista Internacional de Sociologia, C.S.I.C., Madrid, octubre-diciembre de 1988.

(29) F.B. Pérez, art. cit. en la nota 23. 
do fuese inferior al que les ofrecian los colonos franceses en Argelia. Pero si no encontraban trabajo a nivel local, era entonces cuando no tenían más remedio que marcharse a Argelia.

En realidad, había un gran desequilibrio entre el número de habitantes disponible para el trabajo y la capacidad de trabajo en la región del Rif. La colonización agrícola era muy limitada. Consistra sobre todo en algunas explotaciones en las cercanías de Melilla, pertenecientes a la Compañía Española de Colonización, y en algunas granjas entre Monte Arruit y Azib el Midar. Las más prósperas parece que eran las situadas en la orilla izquierda del Muluya en las llanuras de Zebra y del Garet, las cuales, según $L$. Milliot ${ }^{30}$ pudieron aprovechar la experiencia de las explotaciones francesas situadas en la otra orilla.

Este factor interviene de manera importante en lo que respecta al origen tribal de los emigrantes. Las tres cuartas partes $(76,7 \%)$ provienen de cuatro cabilas: Temsamán, Beni Said, Beni Tuzín y Tafersit. En estas regiones la emigración alcanza el 20 por ciento del total de los hombres de 15 a 50 años ${ }^{31}$. Aquí escaseaban las oportunidades de trabajo.

En cambio, las tribus próximas a Melilla como Guelaya, Beni 174 Bu Yahi, Beni Ulichek, Ulad Setut y Metalsa, pese a su proximidad a Argelia en relación con las anteriores, no representan más que 3,3 emigrantes por cien hombres en edad de trabajar ${ }^{32}$.

Ello se debe a que las minas de Beni Bu Ifrur y los pueblos de los alrededores de Melilla proporcionaban a los habitantes numerosas jornadas de trabajo. Pero para el conjunto de la región, hay que decir que estas salidas eran ínfimas en relación con las necesidades de la población.

La penetración de la economfa capitalista en el Rif, aunque revistiese características más modestas y menos acentuadas que en la zona del Protectorado francés, creó en el campesino rifeño la necesidad de un salario. La imposición del tertib ${ }^{33}$ por las autoridades españolas y los años de hambres y sequías hicieron que ese salario fuese aún más indispensable. Durante esos años, el rifeño se deja tentar por las facili-

(30) L. Milliot, art. cit.

(31) Anuario Estadístico, 1942, p. 303.

(32.) Idem.

(33) Tertib: Impuesto directo, cuya base tributaria eran los cultivos anuales, los árboles frutales y los animales. Este impuesto se establecí a partir de 1927, año de la publicación del primer presupuesto. 
dades de crédito que se le ofrecían y pedía prestado, sobre todo mercancras, ya que se trataba, en primer lugar, de comer. Las tasas de interés eran, en general, muy elevadas: 15 duros que había que devolver por 10 prestados durante 3 meses, o tratándose de sémola, ocho medidas que habra que devolver en verano por cinco recibidas en invierno ${ }^{34}$.

Estas altas tasas de interés y las dificultades de la agricultura incitaban al campesino rifeño a buscar un salario. A la necesidad de obtener medios de subsistencia complementarios de los que proporcionaba la explotación tradicional, se sumaba la ventaja de obtener moneda.

\section{La atracción de Argelia}

La colonización de Argelia y la implantación de viñedos en el Oranesado creó una necesidad importante de mano de obra. La roturación de una gran parte de las tierras de colonización del Oranesado se inició con mano de obra española, pero ésta no tardó en asentarse en propiedades adquiridas con su trabajo y dejo de suministrar contingentes suficientes para las labores del campo.

Por otra parte, la población autóctona argelina habra sido desplazada y mostraba poco entusiasmo por trabajar en las explotaciones de los nuevos amos, lo que hacía que éstos la tratasen de "perezosa" 35.

Esta era otra de las razones que alentaba a los rifeños a buscar en la colonización francesa medios complementarios de subsistencia, efectuando los trabajos manuales más penosos. Según varios autores ${ }^{36}$, los colonos franceses estaban muy satisfechos de los trabajos que efectuaban los obreros rifeños, consideraban a éstos excelentes trabajadores y los preferian a los argelinos, ya que podían efectuar cualquier trabajo que se les pidiese sin quejarse. El único fin que perseguían era el de trabajar duro y por mucho tiempo ${ }^{37}$.

(34) L. Milliot, art. cit., p. 315.

(35) En 1933-1934, L. Milliot, con todos los prejuicios habituales de la colonización, escribía: "El elemento indígena local, a menudo rechazado por la oleada europea, era poco resistente en el trabajo y, no mostrando ningún ardor por él, prefería vivir perezosamente de los escasos recursos de su ganadería", véase art. cit. p. 313; en la nota 12.

(36) Especialmente, L. Millió, Du Taillis y F.B. Pérez.

(37) F.B. Pérez nos describe detalladamente las cualidades de los trabajadores rifeños en Argelia. 


\section{Argelia}

\section{Condiciones de salida de los obreros rifeños hacia}

Las salidas tenfan lugar durante todo el año, pero sobre todo en otoño, y los regresos en verano para poder efectuar por lo menos una parte de las faenas agrícolas en sus campos, particularmente las de la trilla (véase cuadro 1)

CUADRO № 1: Clasificación del movimiento migratorio rifeño hacia Argelia, por meses, para los años 1948-1949.

\begin{tabular}{||l|r|r|r|r||}
\hline \multicolumn{3}{|c}{ ENTRADA } & \multicolumn{1}{c|}{ SALIDA } \\
\hline AÑOS & 1948 & 1949 & 1948 & 1949 \\
\hline ENERO & 797 & 836 & 251 & 357 \\
FEBRERO & 743 & 1.996 & 773 & 279 \\
MARZO & 577 & 934 & 355 & 480 \\
ABRIL & 472 & 1.113 & 320 & 621 \\
MAYO & 294 & 928 & 665 & 623 \\
JUNIO & 302 & 466 & 465 & 1.277 \\
JULIO & 321 & 434 & 657 & 984 \\
AGOSTO & 421 & 1.289 & 528 & 884 \\
SEPT. & 584 & 749 & 632 & 2.359 \\
OCTUBRE & 435 & 790 & 358 & 781 \\
NOVIEM. & 469 & 2.305 & 477 & 592 \\
DICIEM. & 579 & 2.388 & 262 & 1.575 \\
& & & & \\
\hline TOTAL & 5.994 & 14.228 & 5.743 & 10.812 \\
\hline
\end{tabular}

FUENTE: Anuario Estadístico de la zona de Protectorado Español en Marruecos 1948-1949. Instituto Nacional de Estadística. Madrid, 1950.

Antes de abandonar el Rif, el obrero preparaba una comida especial a la que invitaba a todos los miembros de la familia y a los 
vecinos. Según L. Milliot ${ }^{38}$, el obrero debía dirigirse a las oficinas de las intervenciones para obtener "un pasaporte" ${ }^{39}$, que se le expedía, sin excesivas formalidades, en una sola hoja sin timbre y sin fotografia a cambio de la módica cantidad de una peseta. La mayoría de las veces, los emigrantes estaban además en posesión de un tarjeta de identidad con fotografía y descripción.

Por lo que sabemos, y según nuestras propias encuestas entre obreros rifeños que habían trabajado en Argelia, eran raros los emigrantes que respetaban estas formalidades administrativas que menciona L. Milliot, sobre todo los que emigraban por vía terrestre y, en general, a pié.

M., un anciano del aduar de Laasara, cabila de Beni bu Ifrur, se acuerda aún de sus largos viajes a pié, en los años cuarenta, hasta la región oranesa en donde trabajaba de obrero (jornalero) en las granjas.

Para su transporte, el trabajador rifeño necesitaba cierto anticipo de dinero, cuando no lo poseŕa, y estaba obligado a pedir prestado o a marcharse a pié exponiéndose a los peligros del camino, como era el caso en los años de hambre en el Rif (1941-1944).

Los obreros que marchaban a pié por primera vez preferían viajar en companfía de antiguos emigrantes que conocían el camino por experiencia. Viajaban siguiendo itinerarios determinados por la experiencia y fijados por la costumbre. En general, había dos itinerarios principales: el que pasaba por Taurirt y llegaba a Uxda, que tomaban sobre todo los de Metalsa y los de Beni Bu Yahi; y el del bajo Muluya, que se atraviesa en el puente internacional de la carretera de Berkán o en los múltiples vados situados aguas arriba o aguas abajo. Una parte de estos emigrantes viajaba a pié y otra utilizaba los autocares que circulaban en la zona española y atravesaban el Marruecos oriental. Por ejemplo, había un autocar que efectuaba regularmente el trayecto Melilla-Uxda, cuyo precio era de 12 a 15 francos en 1931-1932.

Consultando los datos estadísticos que pudieron recogerse durante un afio entero, el de 1931, en relación con uno de los lugares de paso de los emigrantes, cabe llegar a la conclusión de que las cabilas que registraban el mayor número de emigrantes por vía terrestre eran las de

(38) L. Milliot, op. cit., p. 318-319.

(39.) Este tipo de pasaporte era conocido en los medios obreros rifeños como pasaporte "FAKAT" ("FAKAT" quiere decir "sólo"). Con ello se expresaba que dicho pasaporte "sólo" servía para entrar en Argelia. 
Beni Tuzín, Metalsa y Beni Bu Yahi, seguidas de la de Beni Ulichek, Beni Uriaguel, Ulad Setut, y, por último, Kebdana (véase cuadro 2).

Las salidas de los aduares se efectuaban en general en grupos de dos, tres o más, con el fin de evitar los peligros del camino, ya que el viaje no era siempre seguro, sobre todo el regreso. Cualquiera que fuese la estación, gracias al vaivén incesante entre el Rif y Argelia, los interesados se encontraban siempre en número suficiente para proseguir el viaje. Ese movimiento en una y otra dirección les permitfa, por otra parte, informarse progresivamente sobre el estado del mercado del trabajo y el desarrollo de la estación de las faenas agrícolas. Estas informaciones intercambiadas en el camino eran las que los guiaban hacia una $u$ otra región argelina. No era al buen tuntún como los obreros rifeños se presentaban en Argelia, afirma L. Milliot ${ }^{40}$.

Además de los peligros que representaba el viaje a pié, éste no era ventajoso desde el punto de vista económico, ya que el obrero gastaba en tiempo y en comida el equivalente de lo que constaba el transporte en autocar. Sin embargo, la mitad de los emigrantes que seguían la vía terrestre viajaban a pié para evitar las formalidades de control administrativo establecidas para atravesar la zona francesa y penetrar en Argelia.

\section{Impacto de la emigración a Argelia en la sociedad rifeña}

Esta emigración puso a los rifeños en contacto directo con la economía capitalista. El trabajo con los colonos franceses en Argelia fue la primera forma de trabajo asalariado que conocieron los rifeños.

Los impactos social y económico de esta emigración eran importantes, ya que las sumas de dinero que se llevaban al Rif servían no sólo de complemento de los recursos sino también para la adquisición de parcelas de terreno y de mercancías importadas como el azúcar, el té, el jabon, etc.

L. Milliot estimaba en 1932 que las cantidades de dinero que se llevaban al Rif cada año ascendían a unos $\mathbf{5 0}$ millones de francos. En 1952, M. Counil ${ }^{41}$ daba la cifra de mil millones. Gracias a estas sumas

(40) L. Milliot, art. cit., p. 317.

(41) M. Counil, Les travailleurs marocains e Algérie, 1952, Documento de CHEAM. 


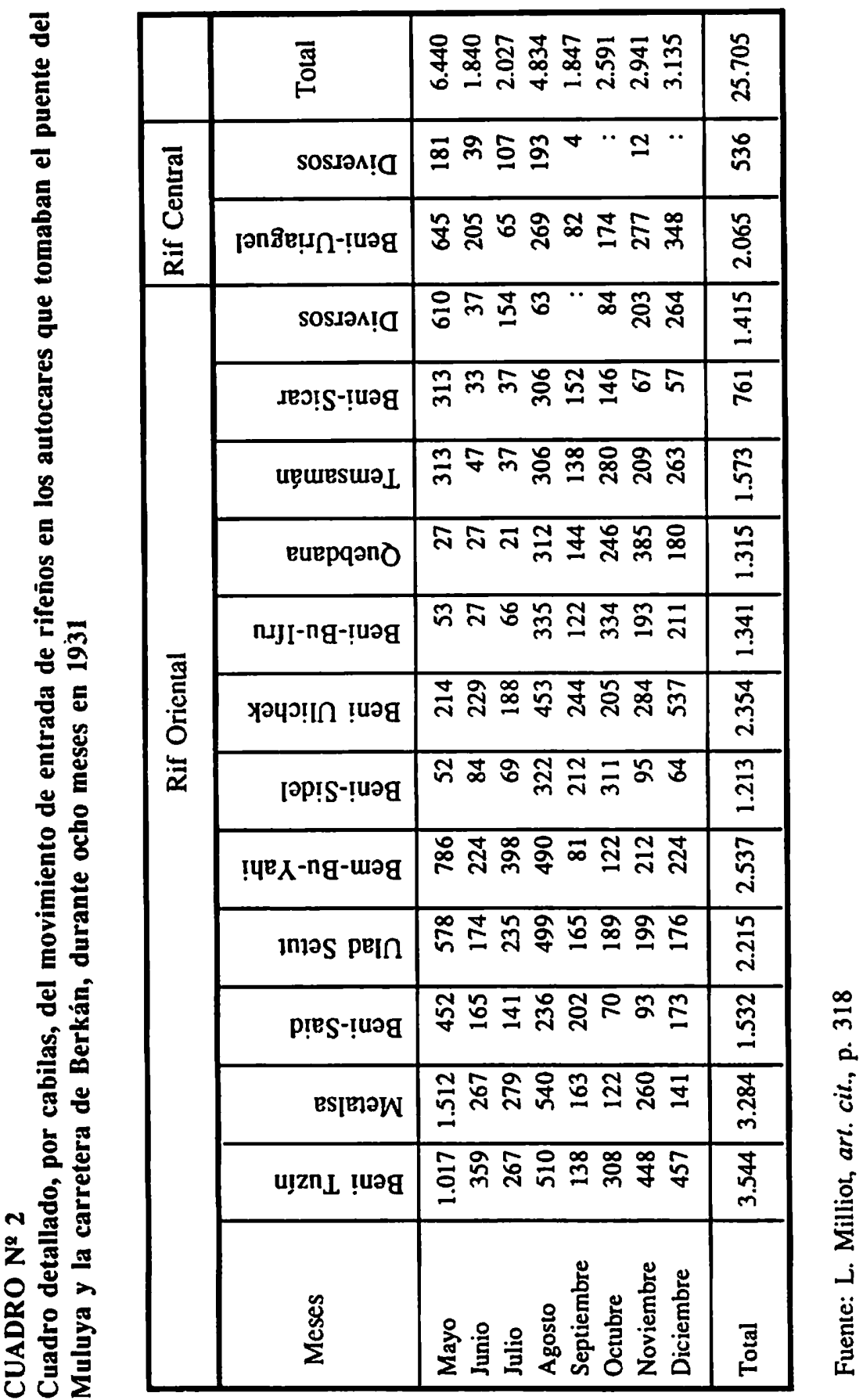


Mimun Ahmed Aziza

CUADRO No 3: Variaciones anuales de la emigración estacional a Argelia en cuatro cabilas rifeñas, de 1946 a 1955

\begin{tabular}{|l|r|r|r|r|r|r|r|r|r|r|}
\hline Años & 1946 & 1947 & 1948 & 1949 & 1950 & 1951 & 1952 & 1953 & 1954 & 1955 \\
\hline Kcbdana & 354 & 343 & 232 & 285 & $?$ & 3.458 & 889 & 625 & 836 & 255 \\
\hline Temsamán & 93 & 529 & 1.412 & 2.950 & $?$ & 2.264 & 3.375 & 4.114 & 3.026 & 1.805 \\
\hline B. Sidcl & 322 & 304 & 31 & 578 & $?$ & 550 & 676 & 416 & 854 & 909 \\
\hline B. Uriagel & 954 & $?$ & 852 & 1.643 & $?$ & 3.680 & 1.667 & 2.538 & $?$ & 245 \\
\hline
\end{tabular}

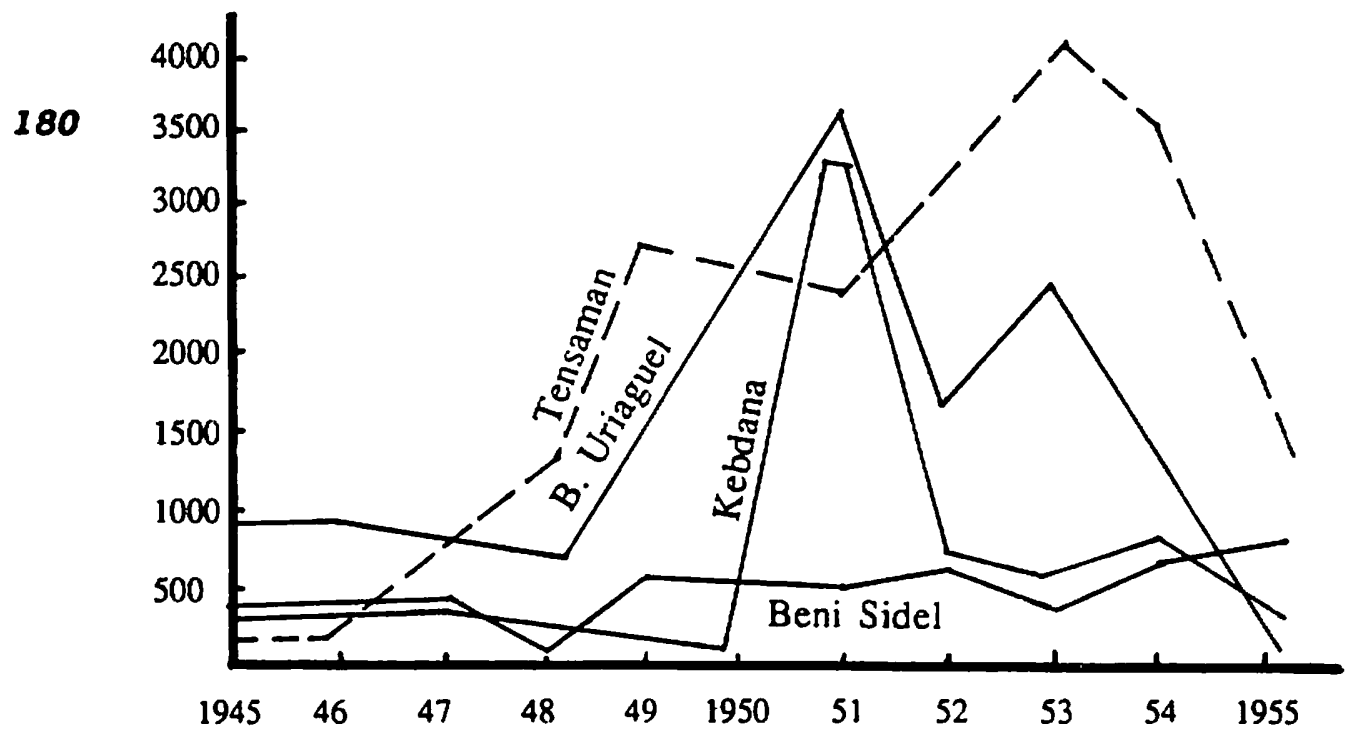


de dinero, el nivel de vida de la población aumentó sin duda progresivamente.

La vida en grupo que llevaban los obreros rifeños en Argelia les permitía ahorrar. Según varios testimonios, el rifefio gastaba la mitad de su sueldo en comida (en Argelia) y llevaba al Rif la otra mitad. M. Counil estima que la cantidad que cada obrero llevaba a su cabila ascendía en 1952 a 27.000 francos, tomando como base un sueldo medio de 300 francos al dia durante un periodo de seis meses al año.

Aparte la comida, los obreros rifeños no hacían ninguna compra dentro del territorio argelino. Las primeras compras las hacían en Uxda.

En conclusión, gracias a la emigración estacional a Argelia, los habitantes del Rif entraron en contacto con la economía europea moderna.

En la década de los años 60 , esa emigración se desvio hacia Europa, y algunos rifeños que continuaron yendo a Argelia, lo hacían sobre todo con el fin de obtener un pasaporte en el consulado de Marruecos en Orán, para poder después trasladarse a Europa. A partir de esos años, la emigración rifeña a Argelia no fue ya más que un recuerdo en la memoria de los viejos rifeños.

En 1976, la expulsión, por las autoridades argelinas, de decenas de miles de marroquíes que vivían en Argelia, reavivó los recuerdos, a veces lejanos, de la emigración. 